\title{
PENGARUH RASIO DIMENSI UTAMA TERHADAP STABILITAS KAPAL PURSE SEINE DI KECAMATAN KUSAN HILIR (STUDI KASUS KAPAL PURSE SEINE KMN BANGUN POLEA 01)
}

\author{
The Effect of Main Dimensional Ratio of Purse Seiner Stabilityi Kusan Hilir District \\ (Case Study of Purse Seiner KMN Bangun Polea 01)
}

Oleh :

Frans Handika Setiawan, Eka Anto Supeni, Aulia Azhar Wahab

Program Studi Pemanfaatan Sumberdaya Perikanan, Universitas Lambung Mangkurat, Indonesia

${ }^{*}$ Korespondensi : franshandika17@gmail.com

\begin{abstract}
Purse seiner vessels include encircling vessels and vessels used to carry purse seine fishing gear whose target fishes are schooling fish when the ship encircles the target must have good ship stability so that the safety and security of fishermen is guaranteed. In determining the stability of the ship, the first thing to consider is when making the ship and determining the ratio of the main dimensions of the ship. The study aims to determine the effect of the ratio of the main dimensions to the stability of the Purse Seine Ship KMN Bangun Polea 01. The method used is the case study method with descriptive analysis and calculation of hydrostatic parameters of the ship. The results showed the ratio of the main dimensions, namely the $L / B$ value of 5.5, the $L / D$ value of 15.71 and the $B / D$ value of 2.85. From the ratio of the main dimensions of the ship that affect the stability of the $B / D$ value.
\end{abstract}

Keywords: ratio of main dimensions, stability, purse seine

\begin{abstract}
ABSTRAK
Kapal purse seine termasuk jenis kapal encircling dan kapal yang digunakan untuk membawa alat tangkap purse seine yang target tangkapannya merupakan ikan yang bersifat schooling fish pada saat kapal melingkari target harus memiliki stabilitas kapal yang baik agar keselamatan dan keamanan nelayan terjamin. Dalam menentukan stabilitas kapal yang paling pertama harus diperhatikan yaitu pada saat pembuatan kapal dan penentuan rasio dimensi utama kapal. Penelitian bertujuan untuk mengetahui pengaruh rasio dimensi utama terhadap stabilitas Kapal Purse Seine KMN Bangun Polea 01. Metode yang digunakan yaitu metode studi kasus dengan analisis deskriptif dan perhitungan parameter hidrostatis kapal. Hasil penelitian menunjukkan rasio dimensi utama yaitu nilai L/B sebesar 5,5 , nilai L/D sebesar 15,71 dan nilai B/D sebesar 2,85. Dari rasio dimensi utama kapal yang berpengaruh terhadap stabilitas yaitu nilai B/D.
\end{abstract}

Kata Kunci : rasio dimensi utama, stabilitas, purse seine

\section{PENDAHULUAN}

Penangkapan ikan merupakan kegiatan untuk memperoleh ikan di perairan yang tidak dalam keadaan dibudidayakan dengan alat atau cara apapun, termasuk kegiatan yang menggunakan kapal untuk memuat, mengangkut, menyimpan, mendinginkan, menangani, mengolah dan mengawetkan (UU No. 45 tahun 2009). Bersadarkan defisini tersebut diketahui bahwa kapal merupakan salah satu komponen penting dalam perikanan tangkap, dimana kapal 
atau perahu penangkapan merupakan sarana pendukung dalam operasi penangkapan ikan sebagai alat transportasi di perairan. Kapal yang baik yaitu kapal yang memiliki keamanan dan kenyamanan pada saat berlayar, terkait hal ini maka stabilitas kapal sangat penting bagi kapal. Kapal yang memiliki stabilitas yang tinggi akan meningkatkan keselamatan serta dapat meningkatkan akselerasi pada saat melakukan penangkapan karena itu pada saat pembuatannya harus diperhatikan agar kapal memiliki stabilitas yang baik.

Menurut Hind (1967) menyatakan bahwa, stabilitas adalah kemampuan kapal untuk kembali ke posisi semula sesudah mengalami kemiringan akibat dari bekerjanya gaya - gaya terhadap kapal. Stabilitas kapal terdiri dari 2 jenis yaitu stabilitas statis dan stabilitas dinamis. Stabilitas statis adalah kecenderungan kapal kembali ke posisi semula setelah mengalami kemiringan pada saat kapal dengan keadaan diam. Hal ini membuktikan bahwa di bawah kondisi biasa kapal tidak selalu dalam keadaan lurus. Kapal secara terus - menerus dipaksa keluar dari posisi lurusnya oleh gaya - gaya dari luar seperti angin dan geleombang.

Kapal purse seine merupakan kapal yang secara khusus dirancang untuk menangkap ikan pelagis yang selalu bermigrasi dalam bentuk schooling fish seperti ikan layang, ikan selar, ikan tongkol dan ikan cakalang dengan alat tangkap jenis purse seine. Prinsip kerja dari alat tangkap purse seine yaitu dengan melingkari gerombolan ikan, sehingga peran dari kapal purse seine sendiri sangat mempengaruhi keberhasilan operasi penangkapan. Pada saat kapal melingkari gerombolan ikan kapal harus memiliki kecepatan serta stabilitas yang baik agar ikan - ikan target tangkapan tidak bisa meloloskan diri.

Dalam menentukan stabilitas kapal yang paling pertama harus diperhatikan yaitu pada saat pembuatan kapal dan penentuan rasio dimensi utama kapal. Menurut Utomo (2010) menyatakan bahwa pada dasarnya sebelum kapal direncanakan untuk dibangun ditentukan dahulu jenis muatan apa yang akan diangkat. Hal ini, penting ditentukan sehubungan dengan besarnya ruangan yang dibutuhkan di dalam kapal untuk mengangkut muatan dalam satuan berat yang sudah ditentukan oleh pemesan, sehingga pembuatan kapal menentukan stabilitas di kapal.

Pembuatan kapal yang dilakukan di Kabupaten Tanah Bumbu masih tradisional hanya dengan pengetahuan dan pengalaman secara turun temurun tanpa didasari dengan perhitungan arsitektur perkapalan (naval architecture) dan gambar rancangan umum (general arangement), gambar rencana garis (line plan), deck profile, body plan dan profile construction (Rusmilyansari et al. 2014). Penelitian bertujuan untuk mengetahui pengaruh rasio dimensi utama terhadap stabilitas Kapal Purse Seine KMN Bangun Polea 01.

\section{METODE}

Penelitian ini dilaksanakan selama 5 bulan mulai dimulai dari kegiatan pembuatan usulan penelitian dan konsultasi, seminar usulan, pelaksanaan penelitian di lapangan, pengolahan data, penyusunan laporan dan konsultasi, seminar hasil, ujian sampai dengan distribusi laporan. Alat yang digunakan selama proses pengambilan data dan penyusunan laporan yaitu meteran rol, mistar kayu, water pass, tali dan pendulum, paku kecil, alat tulis, laptop dan kamera.

Metode yang digunakan yaitu studi kasus, dimana studi kasus merupakan penelitian dimana peneliti menggali suatu fenomena tertentu (kasus) dalam suatu waktu dan kegiatan (program, even, proses, institusi atau kelompok sosial) serta mengumpulkan informasi secara terinci dan mendalam dengan menggunakan berbagai prosedur pengumpulan data selama periode tertentu.

Analisis data menggunakan analisis deskriptif untuk mendeskripsikan desain dan tata ruang muat kapal sampel, analisis rasio dimensi utama kapal dilakukan untuk mengetahui berbagai karakteristik kemampuan kapal, dimana analisis ini meliputi rasio antar panjang dan lebar (L/B), panjang dan dalam (L/D) serta lebar dan dalam (B/D). Selain analisis terhadap rasio dimensi, analisis terhadap nilai - nilai koefisien untuk kapal juga dilakukan. Nilai - nilai ini dibandingkan dengan nilai rasio dimensi utama dan koefisien bentuk kapal Iskandar dan Pujiati (1995).

Perhitungan parameter hidrostatis menggunakan perhitungan naval architecture (Fyson $1985)$ yang digunakan untuk mencari nilai water plan (Aw), Volume Displacement $(\nabla)$, Ton Displacement $(\Delta)$, Block coefficient $(\mathrm{Cb})$, Midship coefficient/Gading besar $(\mathrm{Cm})$, Prismatic coefficient (Cp), Waterplane coefficient (Cw), Ton per Centimeter Immersion (TPI), Jarak titik 
apung (KB), Jarak Metacenter (KM), Jarak titik apung - metacenter longitudinal (BML), Jarak Metacenter Longitudinal (KML).

\section{HASIL DAN PEMBAHASAN}

\section{Deskripsi Kapal Purse Seine KMN Bangun Polea 01}

Menurut Azis et al. (2017), menyatakan bahwa kapal purse seine termasuk kedalam jenis kapal encircling yang digunakan untuk membawa alat tangkap purse seine dengan target tangkapannya merupakan ikan yang bersifat schooling fish. Hal tersebut yang membuat kapal harus memiliki kapasitas dukung yang besar dan sebagai kapal yang membawa alat tangkap yang pengoperasiannya dengan cara dilingkarkan maka kestabilan kapal sangat penting.

Tabel 1 Spesifikasi teknis kapal purse seine KMN Bangun Polea 01

\begin{tabular}{clc}
\hline No. & \multicolumn{1}{c}{ Keterangan } & Jenis dan ukuran \\
\hline 1 & Tipe & Purse seine \\
2 & Bahan & Kayu ulin dan kayu alaban \\
3 & Mesin & Fuso \\
4 & GT kapal & $24 \mathrm{GT}$ \\
5 & Panjang Keseluruhan (LOA) & $22 \mathrm{~m}$ \\
6 & Panjang garis muatan penuh (LWL) & $20 \mathrm{~m}$ \\
7 & Panjang antar garis tegak (LPP) & $19 \mathrm{~m}$ \\
8 & Lebar kapal (B) & $4 \mathrm{~m}$ \\
9 & Tinggi kapal (D) & $1,4 \mathrm{~m}$ \\
10 & Sarat air (d) & $1,12 \mathrm{~m}$ \\
\hline
\end{tabular}

Kapal KMN Bangun Polea 01 yang dijadikan sampel merupakan kapal pribadi milik Bapak Sudir yang telah beroperasi selama kurang lebih 15 tahun. Kapal sampel dibangun digalangan kapal yang ada di Desa Pagaruyung dengan bahan utama pembuatan kapalnya yaitu kayu ulin dan kayu alaban. Kapal dilengkapi dengan mesin fuso dan memiliki kekuatan mesin sebesar 24 GT. kapal sampel memili panjang keseluruhan (LOA) $22 \mathrm{~m}$, panjang garis air (LWL) $20 \mathrm{~m}$, panjang antar garis tegak (LPP) 19 m, lebar kapal (B) 4 m, tinggi kapal (D) 1,4 m dan sarat kapal (d) 1,12 $\mathrm{m}$.

\section{Rasio Dimensi Utama Kapal Purse Seine KMN Bangun Polea 01}

Rasio dimensi utama merupakan hal penting dalam proses pendesainan kapal. Menurut Fyson (1985) dalam Palembang et al. (2013) dalam desain sebuah kapal, karakteristik perbandingan dimensi utama merupakan hal penting yang harus diperhatikan untuk menentukan kapasitas kapal serta mengetahui stabilitas, kekuatan dan kecepatan kapal. Perbandingan dimensi meliputi perbandingan antara panjang dan lebar (L/B), perbandingan antara lebar dan dalam (B/D) dan perbandingan antara panjang dan dalam (L/D).

Tabel 2. Rasio dimensi utama

\begin{tabular}{ccc}
\hline Rasio Dimensi Utama & Nilai Acuan & KMN Bangun Polea 01 \\
\hline L/B & Iskandar dan Pujiati (1995) & 5,5 \\
L/D & $2,60-9,30$ & 15,71 \\
B/D & $4,55-17,45$ & 2,85 \\
\hline
\end{tabular}

Mulyanto et al. (2010) menyatakan kapal membutuhkan stabilitas yang tinggi dikarenakan cara pengoperasian jaring berada pada salah satu sisi lambung yang mengakibatkan tumpuan beban berada di tempat tersebut dan pada saat jaring diangkat ke atas kapal akan mengalami kemiringan. Dalam menentukan stabilitas kapal perlu dilihat nilai rasio dimensi utama kapal yaitu nilai $L / B, L / D$ dan nilai B/D. 
Menurut Iskandar dan Pujiyanti (1995) mengatakan bahwa nilai L/B semakin kecil maka akan berpengaruh buruk terhadap kecepatan kapal karena nilai tahanan geraknya akan semakin besar, jika nilai L/D yang semakin membesar akan berdampak pada melemahnya kekuatan memanjang kapal dan nilai B/D yang semakin besar akan memberikan stabilitas kapal yang baik.

Berdasarkan data nilai L/B yaitu perbandingan antara panjang kapal dan lebar kapal, dalam hal ini kapal memiliki nilai L/B sebesar 5,5 dan sesuai dengan nilai acuan Iskandar dan Pujiyanti (1995), sehingga kapal sampel dikatakan memiliki olah gerak dan kecepatan yang baik. Palembang et al. (2013) menyatakan nilai L/B digunakan untuk menganalisis olah gerak dan kecepatan suatu kapal. Semakin besar nilai L/B suatu kapal maka kecepatan suatu kapal akan semakin besar dan olah gerak kapal semakin baik.

Nilai L/D merupakan perbandingan antara panjang kapal dan tinggi kapal, dalam hal ini kapal memiliki nilai L/D sebesar 15,71 dan sesuai dengan nilai acuan Iskandar dan Pujiyanti (1995), sehingga kapal sampel dikatakan memiliki kekuatan memanjang kapal yang baik. Menurut Palembang et al. (2013) Nilai L/D merupakan nilai kekuatan memanjang suatu kapal, semakin besar nilai L/D, maka akan mengakibatkan kekuatan memanjang kapal melemah.

Nilai B/D merupakan perbandingan antara lebar kapal dan tinggi kapal, dalam hal ini kapal memiliki nilai B/D sebesar 2,85 dan sesuai dengan nilai acuan Iskandar dan Pujiyanti (1995), sehingga kapal sampel dikatakan memiliki stabilitas kapal yang baik. Nilai B/D semakin besar, maka stabilitas kapal dan olah gerak kapal semakin membaik (Novita et al. 2014).

\section{Desain Kapal Kapal Purse Seine KMN Bangun Polea 01}

Berdasarkan Gambar 1, General Arrangement atau rancangan umum kapal sampel diketahui memiliki beberapa ruangan yaitu ruang palka dan ruang alat tangkap ikan, ruang BBM, ruang akomodasi $A B K$, ruang kemudi, dapur, ruang makan, toilet, ruang air bersih, ruang peralatan dan ruang mesin. Pada Gambar 2 menunjukkan lines plan kapal dimana ini digunakan untuk melihat bentuk kapal mulai dari bagian haluan kebagian buritan. Berdasarkan Gambar 2 diketahui pada bagian haluan kapal memiliki bentuk $V$-buttom dan pada bagian tengah sampai buritan kapal memiliki bentuk U-buttom. Hal ini sesuai dengan pernyataan Iskandar (1990) yang menyatakan bahwa pemilihan bentuk $V$-buttom pada bagian haluan sudah tepat karena dapat membelah air dengan baik. Bentuk U-buttom pada bagian tengah sampai kebagian buritan mengarah kebulat dimaksudkan agar olah gerak kapal baik.
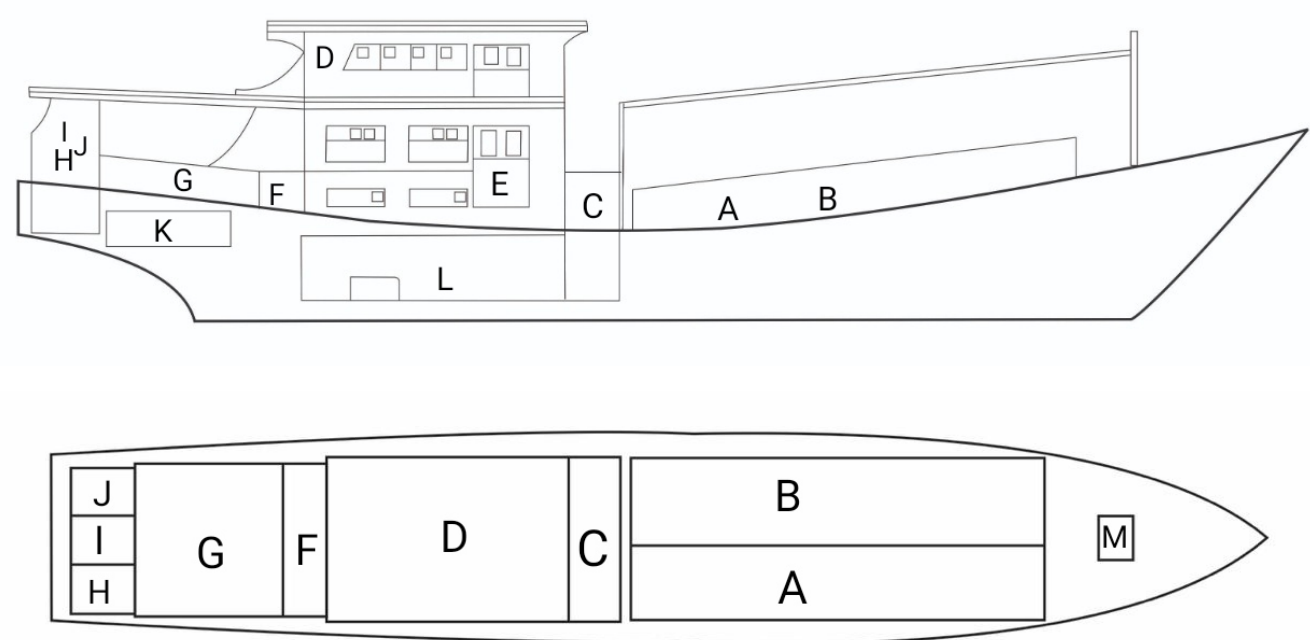

Gambar 1 General Arrangement Kapal Purse Seine KMN Bangun Polea 01 


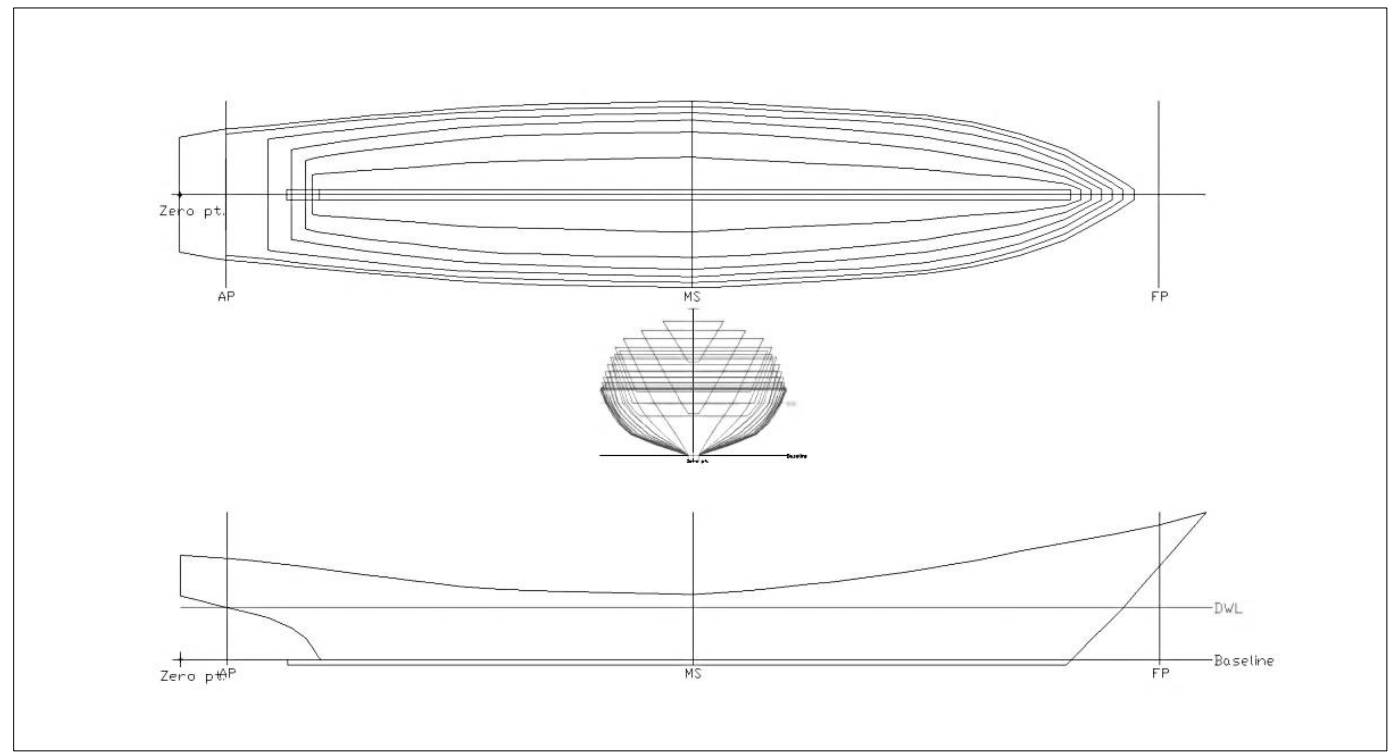

Gambar 2 Lines plan Kapal Purse Seine KMN Bangun Polea 01

\section{Parameter Hidrostatis Kapal}

Nilai-nilai parameter hidrostatik tersebut meliputi nilai volume displacement, ton displacement, waterplan area, midship area, coefficient of fineness, ton per centimetre immersion, longitudinal centre of buoyancy dll. Nilai-nilai dari parameter hidrostatik ini menggambarkan keragaan kapal secara statis (Gillmer dan Johnson 1982; Rawson dan Tupper 1985; Fyson 1985).

Tabel 3 Parameter hidrostatis kapal sampel dalam keadaan kosong

\begin{tabular}{|c|c|c|c|c|c|c|c|}
\hline \multirow{3}{*}{ No. } & \multirow{3}{*}{ Draft Amidships m } & \multirow{2}{*}{$\begin{array}{c}\text { Keel } \\
0,000\end{array}$} & \multicolumn{5}{|c|}{ Waterlines } \\
\hline & & & wl 1 & wl 2 & wl 3 & wl 4 & wl 5 \\
\hline & & 0,000 & 0,224 & 0,448 & 0,672 & 0,896 & 1,120 \\
\hline 1 & Displacement t & 0,4085 & 3,145 & 9,509 & 18,73 & 29,86 & 42,83 \\
\hline 2 & Volume (displaced) $\mathrm{m}^{3}$ & 0,405 & 3,040 & 9,269 & 18,253 & 29,129 & 41,784 \\
\hline 3 & Prismatic coeff. (Cp) & 0,980 & 0,817 & 0,779 & 0,770 & 0,759 & 0,740 \\
\hline 4 & Block coeff. $(\mathrm{Cb})$ & 0,980 & 0,348 & 0,368 & 0,420 & 0,454 & 0,468 \\
\hline 5 & Max Sect. area coeff. $(\mathrm{Cm})$ & 1,000 & 0,427 & 0,473 & 0,546 & 0,598 & 0,633 \\
\hline 6 & Waterpl. area coeff. (Cwp) & 0,963 & 0,764 & 0,785 & 0,807 & 0,825 & 0,833 \\
\hline 7 & LCB from zero pt. (+ve fwd) m & 10,804 & 10,692 & 10,591 & 10,550 & 10,507 & 10,415 \\
\hline 8 & LCF from zero pt. (+ve fwd) m & 10,949 & 10,578 & 10,569 & 10,436 & 10,337 & 10,053 \\
\hline 9 & KB m & $-0,055$ & 0,112 & 0,269 & 0,414 & 0,553 & 0,692 \\
\hline 10 & KG m & 1,120 & 1,120 & 1,120 & 1,120 & 1,120 & 1,120 \\
\hline 11 & BMt m & 0,036 & 0,960 & 1,708 & 1,564 & 1,453 & 1,354 \\
\hline 12 & BML m & 194,834 & 117,452 & 69,169 & 49,673 & 40,098 & 36,232 \\
\hline 13 & GMt m & $-1,139$ & $-0,048$ & 0,857 & 0,858 & 0,887 & 0,926 \\
\hline 14 & GML m & 193,659 & 116,444 & 68,319 & 48,968 & 39,532 & 35,804 \\
\hline 15 & KMt m & $-0,019$ & 1,072 & 1,977 & 1,978 & 2,007 & 2,046 \\
\hline 16 & $\mathrm{KML} \mathrm{m}$ & 194,779 & 117,564 & 69,439 & 50,088 & 40,652 & 36,924 \\
\hline 17 & Immersion (TPc) tonne/cm & 0,036 & 0,207 & 0,363 & 0,460 & 0,540 & 0,619 \\
\hline
\end{tabular}

Berdasarkan data diketahui bahwa waterplane area (Aw) menunjukkan luas area kapal pada garis air tertentu secara horizontal - longitudinal. Nilai Waterplane area pada kapal sampel adalah $60,415 \mathrm{~m}^{2}$. Ton displacement $(\Delta)$ menunjukkan besarnya berat badan kapal di bawah garis air atau menggambarkan berat air yang dipindahkan oleh badan kapal yang terbenam. Semakin besar nilai ton displacement sebuah kapal maka bagian kapal yang terbenam di bawah permukaan air juga semakin tinggi. Nilai ton displacement pada saat draft maksimum adalah 42,83 ton pada WL $1,12 \mathrm{~m}$. Volume displacement $(\nabla)$ menunjukkan volume badan kapal yang berada di bawah garis air. Nilai volume displacement terbesar yang diperoleh pada saat draft maksimum adalah 41,784 $\mathrm{m}^{3}$ pada WI 1,12 $\mathrm{m}$. Nilai-nilai tersebut merupakan kapasitas muatan maksimum yang dapat 
ditampung kapal. Ton per centimeter (TPC) menunjukkan berat yang dibutuhkan untuk merubah draft sebesar $1 \mathrm{~cm}$. Nilai TPc pada kapal sampel adalah 0,619 ton/cm, yang berarti bahwa penambahan atau pengurangan muatan sebesar nilai tersebut ke atau dari dalam kapal akan menambah atau mengurangi sarat air kapal sebesar $1 \mathrm{~cm}$.

\section{Koefisien Bentuk Kapal Purse Seine KMN Bangun Polea 01}

Coefficient of fineness yang biasa disebut sebagai koefisien kegemukan kapal, merupakan salah satu parameter hidrostatik yang mencerminkan bentuk badan kapal. Menurut Ayodhyoa (1972) menyatakan bahwa kapal dapat berbentuk langsing atau gemuk, tergantung pada besaran koefisien bentuk kapal seperti koefisien balok $(\mathrm{Cb})$, koefisien penampang tengah $(\mathrm{Cm})$, koefisien garis air (Cw) dan koefisien prismatik (Cp).

Nilai - nilai koefisien bentuk kapal dibandingkan dengan nilai acuan menurut Iskandar dan Pujiati (1995) sehingga didapatkan hasil perbandingan sebagai berikut :

Tabel 4 Perbandingan koefisien bentuk kapal dengan nilai acuan Iskandar dan Pujiati (1995)

\begin{tabular}{lcccc}
\hline \multicolumn{1}{c}{ Nama } & Cb & Cm & Cw & Cp \\
\hline Iskandar dan Pujiati (1995) & $0,56-0,67$ & $0,78-0,88$ & $0,60-0,79$ & $0,84-0,96$ \\
Kapal Purse Seine KMN & 0,468 & 0,633 & 0,833 & 0,740 \\
Bangun Polea 01 & & &
\end{tabular}

Nilai $\mathrm{Cb}$ bergerak dari $0-1$, semakin mendekati nilai 1 , kapal dikatakan semakin gemuk dan sebaliknya dikatakan ramping jika mendekati nilai 0 . Nilai Coefficient block $(\mathrm{Cb})$ pada kapal sampel adalah 0,468 pada WI 1,12 m, berarti kapal sampel memiliki bentuk lambung langsing sehingga menguntungkan dalam segi kecepatan kapal.

Coefficient of midship $(\mathrm{Cm})$ merupakan perbandingan luas antara penampangan gading besar yang terendam air dengan luas suatu penampang yang lebarnya $B$ dan tinggi $D$. Nilai Coefficient of midship $(\mathrm{Cm})$ pada kapal sampel adalah 0,633 pada $\mathrm{Wl} 1,12 \mathrm{~m}$, hal ini menujukkan bahwa pada bagian midship kapal sampel memiliki bentuk yang gemuk atau round buttom.

Coefficient water plan $(\mathrm{Cw})$ menunjukkan besarnya luas area penampang membujur tengah kapal dibandingkan dengan bidang empat persegi panjang yang mengelilingi luas area tersebut, dimana nilai Coefficient water plan (Cw) pada kapal sampel adalah 0,833 pada Wl 1,12 m, hal ini menunjukkan bahwa kapal sampel memiliki bentuk penampang garis air yang mendekati bentuk empat persegi, sehingga meningkatkan stabilitas kapal.

Coefficient of Prismatic (Cp) adalah perbandingan antara volume badan kapal yang berada dibawah permukaan air dengan volume sebuah prisma dengan luas penampang midship area dan panjang kapal. Nilai Coefficient of Prismatic (Cp) pada kapal sampel adalah 0,740 pada WI 1,12 m. Berdasarkan nilai $\mathrm{Cp}$ kapal sampel diketahui memiliki bentuk badan melebar pada bagian buritan.

\section{SIMPULAN}

Rasio dimensi utama kapal yang berpengaruh terhadap stabilitas yaitu nilai B/D kapal, dimana nilai $B / D$ kapal sampel sebesar 2,85 yang menunjukkan bahwa kapal sampel memiliki stabilitas yang baik.

\section{DAFTAR PUSTAKA}

Ayodhyoa AU. (1972). Fishing Boat. Bogor (ID): Institut Pertanian Bogor.

Azis MA, Iskandar BH dan Novita Y. (2017). Kajian Desain Kapal Purse Seine Tradisional di Kabupaten Pinrang (Studi Kasus KM. Cahaya Arafah). Albacore, 1(1): 69 - 76.

Fyson J. (1985). Design of Small Fishing Vessels. England (UK): Fishing News Book.

Gillmer TC dan Johnson B. (1982). Introduction to Naval Architecture. Maryland (AS): Naval Institute Press. 
Hind JA. (1967). Trim and Stability of Fishing Vessel. First edition. London (UK): Fishing News Books Ltd.

Iskandar BH. (1990). Studi tentang desain dan konstruksi kapal gillnet di Indramayu. Skripsi. Bogor (ID): Fakultas Perikanan dan Ilmu Kelautan, Institut Pertanian Bogor.

Iskandar BH dan Pujiati S. (1995). Keragaan Teknis Kapal Perikanan di Beberapa Wilayah Indonesia (laporan penelitian). Bogor (ID): Jurusan Pemanfaatan Sumber Daya Perikanan, Fakultas Perikanan Perikanan dan IImu Kelautan, Institut Pertanian Bogor.

Mulyanto RB, Wahyono A, Kertorahardjo RSP. (2010). Kapal Perikanan (Pengukuran dan Perhitungan). Semarang (ID): Balai Besar Pengembangan Penangkapan Ikan.

Novita Y, Martiyani N dan Ariyani RE. (2014). Kualitas Stabilitas Kapal Payang Palabuhanratu Berdasarkan Distribusi Muatan. Jurnal IPTEKS Pemanfaatan Sumberdaya Perikanan, 1(1) : $28-39$.

Palembang S, Luasunaung A, Pangalila FTP. (2013). Kajian Rancang Bangun Kapal Ikan Fibreglass Multifungsi 13 GT di Galangan Kapal CV. Cipta Bahari Nusantara Minahasa Sulawesi Utara. Jurnal Ilmu dan Teknologi Perikanan Tangkap, 1(3): 87-92.

Rawson KJ dan Tupper EC. (1989). Basic Ship Theory. Volume 1. England (UK): Longman Scientific \& Technical. Longman Group UK Limited.

Rusmilyansari, Iriansyah dan Aminah S. (2014). Pembangunan Kapal Perikanan Di Galangan Kapal Tradisional Kalimantan Selatan. Fish Scientiae, 4(8): 95 - 109.

[UU] Undang - Undang Republik Indonesia. (2014). Undang-Undang RI Nomor 31 Tahun 2004 tentang Perikanan.

Utomo B. (2010). Pengaruh Ukuran Utama Kapal terhadap Displacement Kapal. Teknik, 31(1): 8489. 